\title{
NILAI-NILAI PENDIDIKAN DAN PENGARUHNYA TERHADAP HUBUNGAN SOSIAL ANAK DALAM NOVEL TOTTO-CHAN KARYA TETSUKO KUROYANAGI
}

\author{
Nur Hastuti \\ Fakultas Ilmu Budaya Universitas Diponegoro \\ Email: nuha_chan@yahoo.com
}

\begin{abstract}
This title research is Education values and the effects toward children social relationship in the novel of Totto-chan by Tetsuko Kuroyanagi.

The object research is Novel Madogiwa No Tottochan by Tetsuko Kuroyanagi that is published in 1981. This research has aim to get description of education values and the effects toward children social relationship in the novel of Totto-chan. The approach method to answer both problems is literary sociology approach. Litetature has relation with people in the society, the effort of people to addapt and change society. Sociology is objective and scientific study about human in society, study about institution and social process. The difference between literature and sociology is sociology does scientific and objective analysis. In other hand, literature infiltrates and penetrates social life and shows human ways to comprehend society with their feeling.

The teaching result of education values and the effects for the children social relationship are:

1. Want to listen what the students tell.

We must respect each other and appreciate to the others. It happens when people is speaking to us, so we must pay attention and listen well. The social relationship with everyone created by communication can run well.

2. Give self confidence.

When we give trust to the others to do their tasks, so we must believe that person can responsible for their task, so that that person can be success in their task. When we give believe to the other person to overcome their problem, so we have to be sure that they can do it well. The trust between one and others create harmonious social relationship.

3. Delete unpretentious feeling in disable children.

Whoever our frien, we must love them eventhough they have lack (disable). Teacher Kobayashi also teach that children or students can not underestimate those disable person. This case makes children in Tomoe love each other, so that social relationship like friendship will create well without underestimate each other.
\end{abstract}

Keywords: novel. values, education, social relationship, literary sociology

\section{PENDAHULUAN}

Sastra merupakan produk masyarakat. Ia berada ditengah masyarakat karena dibentuk oleh anggota-anggota masyarakat berdasarkan desakan-desakan emosionil atau rasionil dari masyarakatnya (Jacob Sumarjo, 1979: 12). Sastra atau lebih dikenal dengan karya sastra adalah hal yang tidak dapat dilepaskan dalam suatu masyarakat tertentu. Keberadannya oleh banyak kalangan merupakan replika kondisi suatu masyarakat. Ini berarti karya sastra memang diciptakan pengarang sebagai mahluk sosial dan untuk orang-orang lain, bukan untuk dirinya sendiri. 
Ketika menulis sebuah karya, seorang pengarang tidak memikirkan; apakah hasil karya yang ia tulis nantinya akan mempunyai makna yang luas bagi masyarakat atau meledak di pasaran. Pengarang menulis sebuah karya yang memang mencerminkan kondisi masyarakat pada zamannya. Menurut Damono, pandangan ini beranggapan bahwa sastra merupakan cermin langsung dari berbagai segi struktur sosial, hubungan kekeluargaan, dan lain-lain. Tema dan gaya sastra yang bersifat pribadi itu, harus diubah menjadi hal-hal yang sifatnya sosial (2003:14). Salah satu contohnya novel yang berasal dari Jepang yang berjudul Totto-chan. Novel Tottochan merupakan novel karya Tetsuko Kuroyanagi yang bertemakan pendidikan yang secara khusus ia tulis untuk mengenang seorang pendidik, pendiri sekaligus Kepala Sekolah Tomoe Gakuen yang bernama Sosaku Kobayashi. Semua peristiwa dalam novel ini diambil dari kisah nyata Totto-chan, nama kecil dari Tetsuko Kuroyanagi.

Novel ini dicetak pertama kali pada tahun 1981 oleh Kodansha dan terjual 4.500.000 novel dalam setahun sehingga membuat sejarah di dunia penerbitan Jepang. Dorothy Britton mengalihbahasakan novel ini dalam Bahasa Inggris pada tahun 1984. Novel ini telah dipublikasikan dalam edisi Bahasa Inggris lebih dari 30 negara di seluruh dunia. Novel Totto-Chan dalam edisi Bahasa Indonesia sudah memasuki cetakan ke delapan. Hal ini menunjukkan bahwa novel tersebut sangat menarik perhatian pembaca baik di Jepang pada khususnya maupun Indonesia serta di seluruh dunia pada umumnya. Novel tersebut telah menginspirasi banyak pendidik sehingga menjadi acuan wajib untuk pendidikan di Jepang. Akibat dari suksesnya novel pertamanya itu, tahun 1984 Tetsuko ditunjuk sebagai duta perempuan asia pertama di Unicef untuk membantu anak-anak yang kelaparan dan menderita di negara berkembang seperti Asia dan Afrika. ${ }^{1}$

Novel Totto-chan ini sarat dengan nilai pendidikan serta bermanfaat bagi mereka yang ingin memahami tentang pendidikan. Novel ini patut dibaca oleh para guru dan anak-anak sekolah. Totto-chan gadis cilik berumur 7 tahun memang sering melakukan perbuatan yang aneh, menjengkelkan dan mencemaskan bagi orang dewasa. Dia suka mengikuti imajinasinya dan

http://www.unicef.org/people/people tetsuko kuroy anagi.html bertindak impulsif. ${ }^{2}$ Hal itu dianggap aneh oleh guru sekolahnya. Totto-Chan dianggap sebagai anak yang nakal, pengacau dan tidak tahu aturan. Dia suka membuka tutup meja berkali-kali, berdiri di depan jendela untuk memanggil pemusik jalanan sampai mengajak berbicara burung walet di saat sedang mengikuti pelajaran, membuat ibu gurunya tidak tahan lagi dan meminta Ibu Tottochan untuk memindahkan Totto-chan ke sekolah lain.

Namun, hal itu tidak membuat Ibunya(Totto-chan), mengatakan kepada Tottochan bahwa ia dikeluarkan dari sekolah. Tottochan tidak akan mengerti mengapa ia dianggap berbuat salah dan ibu Totto-Chan tidak ingin anaknya menderita tekanan batin. Setelah dikeluarkan dari sekolah kemudian Ibu Totto-chan mendaftarkan ke sebuah sekolah bernama TomoeGakuen, sebuah sekolah unik yang terletak di alam bebas dengan gerbong kereta sebagai ruang kelasnya. Totto-chan terlihat gembira sekali membayangkan ia akan belajar di sebuah gerbong kereta sambil memandangi keindahan alam di balik jendela kelasnya tersebut, serasa bukan sekolah tetapi melakukan perjalanan rekreasi. Sungguh beruntung Ibu Totto-chan bertemu dengan Pak Kobayashi, seorang pendidik idealis yang berusaha melihat dunia dari kaca mata anakanak.

Bagi Kobayashi, pendiri dan pendidik di sekolah Tomoe (Tomo Gakuen), tidak ada tingkah Totto-chan yang perlu dikhawatikan. Baginya, semua yang dilakukannya itu tidak lebih dari naluri anak dengan luapan ekspresinya yang tidak bisa diam dan selalu merasa ingin tahu. Pak Kobayashi memperlakukan murid-murid, termasuk Totto-chan, dengan cara tidak biasa ketika memberikan pelajaran di Tomoe. Kobayashi menganggap semua anak dilahirkan dengan sifat yang baik, yang kadang-kadang jadi buruk karena pengaruh lingkungan dan kelakuan buruk dari orang dewasa. Kobayashi berusaha menemukan watak baik dari tiap-tiap anak dan mengembangkannya agar kelak menjadi orang dewasa yang mempunyai kepribadian khas. Salah satunya Totto-chan, ia berkembang menjadi anak yang pandai, memiliki pribadi yang menyenangkan dan akhirnya menjadi penulis handal.
${ }^{2}$ Bersifat cepat bertindak secara tiba-tiba menurut gerak hati 
Tomoe Gakuen didirikan oleh Kobayashi di Tokyo pada 1937, beberapa saat setelah ahli pendidikan yang sangat mencintai anak-anak ini pulang dari menimba ilmu di Eropa. Menurut Tetsuko, diterimanya model pendidikan yang tidak konvensional itu, karena Kobayashi tidak mempublikasikan sistem pendidikannya, sehingga tidak mengundang perhatian banyak masyarakat. Setelah pemerintah Jepang yakin, bahwa model pendidikan Kobayashi, ditataran anak-anak itu tidak membawa akibat secara langsung bagi kestabilan politik Jepang. Alasan lain bahwa Kobayashi sendiri adalah tokoh yang sangat dihormati di Departemen Pendidikan. Tomoe Gakuen mempunyai keistimewaan yang membedakan dengan sekolah lain. Hal itu bukan karena ruang kelasnya dari bekas gerbong kereta api, melainkan nilai-nilai pendidikannya yang sangat bagus sehingga membawa pengaruh baik terhadap hubungan sosial anak yang bersekolah di Tomoe Gakuen.

\section{RUMUSAN MASALAH}

Berdasarkan uraian di atas, permasalahan yang penulis bahas adalah:

1. Apa saja nilai-nilai pendidikan yang terdapat dalam novel Totto-chan.

2. Apa saja pengaruh nilai-nilai pendidikan terhadap hubungan sosial anak dalam novel Totto-chan.

\section{LANDASAN TEORI}

Penelitian terhadap novel Auto menggunakan teori Sosiologi Sastra. Sastra berurusan dengan manusia dalam masyarakat: usaha manusia untuk menyesuaikan diri dan usahanya untuk mengubah masyarakat itu (Damono, 2003:11). Adapun sosiologi adalah telaah yang objektif dan ilmiah tentang manusia dalam masyarakat; telaah tentang lembaga dan proses sosial ((Damono, 2003:10). Perbedaan yang ada antara keduanya adalah bahwa sosiologi melakukan analisis ilmiah yang objektif, sedangkan sastra menyusup menembus permukaan kehidupan sosial dan menunjukan cara-cara manusia menghayati masyarakat dengan perasaannya. Menurut Wiyatmi, pendekatan ini dilatarbelakangi oleh fakta bahwa keberadaan karya sastra tidak dapat terlepas dari realitas sosial yang terjadi dalam masyarakat (2009:97).

Dalam sosiologi pembaca dan dampak sosial karya sastra ditelaah sejauhmana sastra ditentukan atau tergantung dari latar sosial, perubahan dan perkembangan sosial.

\section{PEMBAHASAN}

Pendidikan dalam Kamus Besar Bahasa Indonesia (2002: 263 ) adalah proses pengubahan sikap dan tingkah laku seseorang atau kelompok orang dalam usaha mendewasakan manusia melalui upaya pengajaran dan pelatihan; proses, cara, perbuatan mendidik. Pendidikan dan pengajaran merupakan indikator-indikator mobilitas sosial, sekaligus kunci untuk memasuki tangga kehidupan bangsa yang lebih tinggi (bdk. Wertheim melalui Nyoman Kutha Ratna, 2003:255). Novel adalah suatu hasil karya sastra, dianggap memiliki nilai pendidikan apabila mempunyai nilai-nilai yang patut ditiru, diajarkan serta membawa dampak yang positif/baik terhadap pembacanya sehingga dapat diwariskan ke generasi selanjutnya.

Sebenarnya apa saja nilai-nilai pendidikan yang diajarkan oleh Kobayashi di Tomoe Gakuen, termasuk Totto-chan sehingga berpengaruh terhadap hubungan sosial mereka. Berikut ini adalah nilai- nilai pendidikan dan pengaruhnya terhadap hubungan sosial anak, yaitu sebagai berikut:

1. Mau Mendengarkan Apa yang Diceritakan oleh Muridnya

Jarang sekali seorang guru mau mendengarkan cerita/curahan hati dari muridnya sampai berjam-jam, mungkin sebagian guru menganggap hal semacam itu membuang waktu, tetapi tidak dengan Kobayashi. Ia mendengarkan dengan penuh perhatian, serta menanggapi apa yang sedang diceritakan oleh Totto-chan. Pengalaman tersebut bagi Totto-chan sangat berkesan karena baru pertama kali dalam masa kanak-kanaknya bertemu dengan orang dewasa seperti Kobayashi yang mau menyediakan waktu lebih dari tiga jam untuk mendengar curahan hatinya tanpa marah, merasa bosan atau pun menguap. Seperti terlihat dalam kutipan berikut ini. 
の。そしてその長い時間のあいだ、一 度だって、あくびをしたり、退屈そう にしないで、トットちゃんが話してる のと同じように、身をのり出して、一 生懸命、聞いてくれたんだもの。 『Kuroyanagi:33』

“ Totto-chan merasa dia telah bertemu dengan orang yang benar- benar disukainya. Belum pernah ada orang yang mau mendengarkan dia sampai berjam-jam seperti kepala sekolah. Lebih dari itu, Kepala sekolah sama sekali tidak menguap atau tampak bosan. Dia selalu tampak tertarik pada apa yang diceritakan Tottochan, sama seperti Totto-chan sendiri." (Kirana: 27)

Dalam Kutipan kalimat di atas, guru Kobayashi ingin mengajarkan kepada anak/muridnya (Tottochan) tentang hubungan sosialnya dengan orang lain baik di sekolah atau di masyarakat jika kelak dia dewasa nantinya, bahwa kita harus saling hormat menghormati dan menghargai kepada orang lain. Seperti, saat ada orang sedang berbicara kepada kita, maka kita harus memperhatikan dan mendengarnya dengan baik. Sehingga komunikasi dapat berjalan dengan baik dengan siapapun.

\section{Memberikan Kepercayaan Diri}

Kobayashi menanamkan kepercayaan diri pada anak-anak untuk dapat menyelesaikan masalahnya sendiri, seperti pada saat dompet Totto-chan jatuh ke kakus/WC, LALU mengeluarkan seluruh kotoran ke permukaan tanah dengan gayung. Ia memang mempunyai alasan, bahwa ia ingin mengambil dompetnya yang terjatuh di dalam bak penampungan kotoran, ia ingin mengetahui dan mengintip ke dalam lubang gelap kakus tersebut. Mungkin kalau orang lain melihat apa yang dilakukan Totto-chan akan marah-marah atau malah menghukum. Tetapi tidak dengan Kobayashi, saat melewati tempat itu, bukan hukuman atau marah yang diterima Tottochan melainkan perkataan yang ramah dan tenang, Seperti kutipan berikut ini:

$$
\text { 『終わったら、みんな、もどしとけよ』 }
$$

『Kuroyanagi:70』
“ Kau akan mengembalikan semuanya kalau sudah selesai kan?" (Kirana :57 ).

Mendapatkan tanggapan yang baik dari Kobayashi seperti pada kutipan di atas, TottoChan pun memasukkan kembali kotoran dalam lubangnya, juga memasukkan tanah yang basah, kemudian meratakan tanah, menutup kembali lubang itu dengan rapi lalu mengembalikan gayung yang dipinjamnya dari gudang tukang kebun. Walaupun dompetnya belum ditemukan tetapi ia sudah merasa puas karena telah mengerahkan segala kekuatan saat mencarinya, kepuasan lain yang dirasakan Totto-chan adalah kepercayaan yang diberikan kepala sekolah dengan tidak memarahinya. Seperti terlihat dalam ungkapan berikut ini.

$$
\begin{aligned}
& \text { でも、もうトットちやんには、なくても、 } \\
& \text { 満足だった。自分で、これだけ、やっ } \\
& \text { てみたのだから。本当は、その満足の } \\
& \text { 中に、『校長先生が、自分のしたこと } \\
& \text { を、おからないで、自分のことを信頼 } \\
& \text { してくれ、ちゃんとした人格をもっ } \\
& \text { た人間として、あつかってくれた』と } \\
& \text { いうことがあったんだけど、そんな難 } \\
& \text { しいことは、トットちやんは、まだ分 } \\
& \text { からなかった。『Kuroyanagi:71』 }
\end{aligned}
$$

“ Tapi Totto-chan tidak peduli. Ia puas karena telah mengerahkan seluruh kemampuannya untuk mencari dompet itu. Kepuasan Totto-chan adalah hasil rasa percaya diri yang ditanamkan kepala sekolah dengan mempercayainya dan tidak memarahinya. Tapi tentu saja hal itu terlalu rumit untuk bisa dimengerti Totto-chan saat itu" (Kirana: 59 )

Dalam Kutipan kalimat di atas, guru Kobayashi ingin mengajarkan kepada anak/muridnya (Tottochan) tentang hubungan sosialnya dengan orang lain baik di sekolah atau di masyarakat jika kelak dia dewasa nantinya, bahwa pada saat kita memberikan kepercayaan kepada orang lain untuk melaksanakan tugasnya, maka kita harus percaya bahwa orang tersebut dapat bertanggungjawab atas tugas yang diberikan kepadanya sehingga orang tersebut dapat berhasil dalam melaksanakan tugasnya. Atau saat kita memberikan kepercayaan orang lain untuk menyelesaikan persoalan yang sedang ia hadapi maka kita harus yakin bahwa orang tersebut dapat menyelesaikan pekerjaannya 
dengan baik. Sehingga kepercayaan yang terbina baik antara satu dengan yang lain menciptakan hubungan yang harmonis.

\section{Menghilangkan Rasa Rendah Diri pada Anak yang Memiliki Keterbatasan}

Anak- anak yang bersekolah di Tomoe tidak hanya anak-anak yang bertubuh normal tetapi juga anak-anak yang mempunyai keterbatasan/cacat, misalnya anak penderita polio dan lain-lain. Biasanya anak yang mempunyai keterbatasan dalam tubuhnya akan merasa minder terhadap temannya. Untuk mengatasi hal itu, pada saat pelajaran renang, Kobayashi menganjurkan agar anak-anak telanjang ketika berenang, dengan cara tidak memaksa. Ia pun yakin, dalam dunia anakanak, yang wajar adalah anak-anak yang punya rasa keingintahuan sesuai dengan usianya tentang perbedaan jenis kelamin. Ia menanamkan suatu pelajaran, bahwa semua tubuh itu indah sehingga anak-anak yang mempunyai cacat tubuh sejak usia dini tidak minder dan berusaha tidak menutupi kecacatannya dalam pakaian. Ia ingin anak-anak merasakan penerimaan orang lain terhadap kecacatannya.

Kobayashi berpendapat kalau anak-anak bertelanjang, maka rasa malu dan rendah diri akan hilang. Seperti kutipan berikut ini.

と校長生徒は、生徒たちに教えたかった。 トモエの生徒の中には、泰明ちゃんのよ うに、小览麻痺の子や、背が、とても小 さい、というような、ハンディキャップ を持ったこも、何人かいたから、裸にな って、一緒に遊ぶ、ということが、そう いう子供たちの差恥心を取り除き、ひい ては、列等意識を持たさないのに立つの では、ないか、と、校長生徒は、こんな ことも教えていたのだった。

『Kuroyanagi:88』

“ Ia ingin mengajarkan kepada anak-anak bahwa semua tubuh itu indah. Di antara murid-murid Tomoe ada yang menderita polio, seperti Yasuaki-chan, yang badannya sangat kecil, atau yang cacat. Kepala sekolah berpendapat jika mereka bertelanjang dan bermain bersama, rasa malu mereka akan hilang dan itu akan membantu mereka menghilangkan rasa rendah diri." ( Kirana: 73 ).
Apa yang ajarkan oleh Kobayashi itu terbukti kebenarannya, seperti kutipan berikut ini:

$$
\begin{aligned}
& \text { 初めは恥ずかしそうにしていたハンデ } \\
& \text { イキャップを持っている子も、そのう } \\
& \text { ち平気になり、楽しいことのほうが先 } \\
& \text { きたって、「恥ずかしい」なんて、気 } \\
& \text { 持ちは、いつのまにか、なくなってい } \\
& \text { た。『Kuroyanagi:88』 } \\
& \text { “ mula-mula anak-anak yang cacat merasa } \\
& \text { malu, tapi perasaan itu segera hilang, dan } \\
& \text { akhirnya mereka benar-benar berhasil } \\
& \text { menghilangkan rasa malu mereka.” } \\
& \text { ( Kirana: } 73 \text { ). }
\end{aligned}
$$

Dalam Kutipan kalimat di atas, guru Kobayashi ingin mengajarkan kepada anak/muridnya (Tottochan) tentang hubungan sosialnya dengan orang lain baik di sekolah atau di masyarakat jika kelak dia dewasa nantinya, bahwa siapapun teman kita maka kita harus tetap menyayangi mengasihi teman kita meskipun ia memiliki keterbatasan (cacat). Guru Kobayashi juga mengajarkan bahwa seorang anak/murid tidak boleh merendahkan orang lain yang memiliki kekurangan. Hal ini membuat anak/murid di Tomoe saling mengasihi dan menyayangi satu dengan lainnya. Sehingga hubungan sosial seperti berteman akan terjalin dengan baik tanpa saling menjatuhkan dan merendahkan.

4. Melatih Anak untuk Berani Berbicara di depan Orang banyak dan Mendengarkan dengan Baik saat Orang Lain Berbicara Dengan Kita

Biasanya seorang anak takut untuk mengungkapkan gagasannya di depan umum, takut salah atau ditertawakan oleh temantemannya. Oleh karena itu, Kobayashi mengajarkan anak agar mau menceritakan sesuatu pada saat makan siang secara bergantian dengan tema bebas tanpa rasa takut. Kobayasahi tidak menuntut anak untuk dapat berbicara seperti pembicara yang baik, ia lebih menekankan anak untuk bebas berbicara tentang apa pun yang disukai. Hal itu akan membuat anak berani bicara/mengeluarkan pendapatnya di dalam kelas/di depan orang tanpa ada rasa takut. Seperti terlihat dalam kutipan berikut.

$$
\begin{aligned}
& \text { このあいだ、校長生徒が、「みんな、も } \\
& \text { っと話が上手になったほうが、いいな。 }
\end{aligned}
$$


どうだい、今度から、お弁当の時、みん なが食べてる間、毎日、違う誰さんが、 ひとり、みんなの輪のまん中に入って、 お話する、ってのは?」

『Kuroyanagi:140-141』

"Pada suatu hari kepala sekolah berkata," Kurasa kita semua harus belajar berbicara lebih baik. Bagaimana menurut kalian? Mulai sekarang, sementara makan siang, kita akan meminta seseorang, bergantian dengan yang lain, berdiri di tengah lingkaran dan menceritakan sesuatu kepada kita. Bagaimana menurut kalian?” (Kirana: 121)

そして、もう一つ、（これから子供は、 人の前に出て、自分の考えを、はっきり と自由に、恥ずかしがらすに表現できる ようになることが、絶対に必要だ）と考 えていたから、そろそろ始めてみよう、 と決めたのだった。『Kuroyanagi:141』

"Kecuali itu, dia berpikir penting bagi mereka untuk berlatih berdiri di depan orang banyak dan mengungkapakan gagasan mereka dengan jelas dan bebas tanpa merasa malu. Begitulah Kepala sekolah mempraktekkan gagasannya.” (Kirana: 122)

「いいかい。上手にお話しようとか、そ うなふうに思わなくていいんだよ。そし て話も、自分のしたいこと、なんでもい いからね。とにかく、やってみようじゃ ないか?」『Kuroyanagi:142』

" kalian tidak perlu merasa harus jadi pembicara yang baik."katanya. " Kalian boleh berbicara tentang apa yang ingin kalian lakukan. Apa saja. Yang penting, mari kita coba dulu." ( Kirana: 123 )

Dalam Kutipan kalimat di atas, guru Kobayashi ingin mengajarkan kepada anak/muridnya (Tottochan) tentang hubungan sosialnya dengan orang lain baik di sekolah atau di masyarakat jika kelak dia dewasa nantinya, bahwa anak/murid harus mempunyai keberanian dan tidak boleh takut saat mengungkapkan ide/pendapat di depan orang lain. Tidak perlu risau/kwatir dulu sebelum menyampaikan, yang penting kita harus mencoba dan berusaha terlebih dahulu. Guru Kobasahi juga menyakinkan kepada anak/muridnya bahwa ketika menyampaikan ide kepada orang lain tidak harus menjadi pintar atau hebat yang penting menyampaikan gagasan terlebih dulu, apakah nanti ide diterima atau tidak, hal tersebut tidak boleh dijadikan beban, yang paling penting telah mencoba.

Hubungan sosial yang baik adalah saat kita bergantian mendengarkan apa yang kita atau orang lain sampaikan/bicarakan, sehinga sikap saling menghormati dan menghargai akan terwujud.

5. Mengajarkan Pada Anak untuk Mendapatkan sesuatu dengan Bekerja Keras / Dengan Jerih Payah Sendiri

Kobayashi mengajarkan pada anak jika menghendaki sesuatu itu harus dengan kerja keras, hal itu diajarkan oleh Kobayashi pada saat perayaan hari olah raga diadakan perlombaan. Apabila ingin jadi pemenang, baik pemenang 1,2 , atau 3 , harus berusaha dengan keras untuk menggapainya. Hadiah yang diberikan adalah hadiah berupa sayuran. Mungkin dengan hadiah sayuran Kobayashi berharap jerih payah anak-anak Tomoe tidak hanya dinikmati oleh anak itu sendiri tetapi juga oleh keluarganya agar dapat merasakan kebahagiaan bersama-sama. Seperti tercermin dalam kutipan berikut.

（...）今晚、お母さんに、これを野菜しても らってごらん？君達が自分で手に入机た野菜 だ。これで、家の人みんなの、おかずが出来 るんだぞ。いいじゃないか! きっとうまいぞ。 『Kuroyanagi:142』

“ (...) Minta Ibu kalian memasaknya untuk makan nanti malam. Itu sayuran yang kalian peroleh dengan usaha kalian sendiri. Kalian telah memberi makanan untuk keluarga dengan jerih payah kalian sendiri. Hebat, kan? Aku yakin, rasanya pasti sedap!" (Kirana: 137 )

Dalam Kutipan kalimat di atas, guru Kobayashi ingin mengajarkan kepada anak/muridnya (Tottochan) tentang hubungan sosialnya dengan orang lain baik di sekolah atau di masyarakat jika kelak dia dewasa nantinya, bahwa dalam hidup ini kita harus mempunyai semangat kerja keras ketika ingin menggapai/mewujudkan sesuatu. Guru Kobayashi juga menyakinkan dengan memberi motivasi dan kepercayaan bahwa apapun kerja keras yang kita lakukan akan membuahkan hasil yang baik dan manis. Hal ini membuat anak/murid menjadi 
berusaha untuk melakukan hal-hal yang disukai dengan kerja keras.

\section{SIMPULAN}

Karya sastra juga mengilhami dan membawa manfaat yang baik bagi pembaca dan masyarakat. Hal itu dapat dilihat dari hasil karya sastra yang ditulis oleh Tetsuko. Ia tidak pernah membayangkan sebelumnya bahwa karyanya tersebut berdampak luas dan mempunyai makna bagi dunia pendidikan. Bahkan novel ini telah menjadi buku wajib untuk pendidikan di Jepang (Tetsuko, 2003: 260).

Seorang anak yang didik dengan baik dan memperoleh pengaruh yang tepat dari orang dewasa baik oleh guru sekolahnya maupun lingkungannya akan dapat membuatnya dapat beradaptasi dan membawa pengaruh baik dalam hubungan sosial anak dengan lingkungannya dan menjadi pribadi yang pandai menyesuaikan diri dengan orang lain. HaI ini seperti yang digambarkan oleh Kobayashi bahwa dalam membimbing mental murid-muridnya, dia berusaha menumbuhkan rasa percaya diri, ketegaran, dan rasa menghargai orang lain, seperti apapun keadaan orang itu.

Novel ini juga mengajarkan nilai-nilai pendidikan dan pengaruhnya bagi hubungan sosial anak/murid di masyarakat nantinya, yaitu sebagai berikut:

1.Mau Mendengarkan Apa yang Diceritakan oleh Muridnya

Kita harus saling hormat menghormati dan menghargai kepada orang lain. Seperti, saat ada orang sedang berbicara kepada kita, maka kita harus memperhatikan dan mendengarnya dengan baik. Sehingga komunikasi dapat berjalan dengan baik dengan siapapun.

\section{Memberikan Kepercayaan Diri}

Pada saat kita memberikan kepercayaan kepada orang lain untuk melaksanakan tugasnya, maka kita harus percaya bahwa orang tersebut dapat bertanggungjawab atas tugas yang diberikan kepadanya sehingga orang tersebut dapat berhasil dalam melaksanakan tugasnya. Atau saat kita memberikan kepercayaan orang lain untuk menyelesaikan persoalan yang sedang ia hadapi maka kita harus yakin bahwa orang tersebut dapat menyelesaikan pekerjaannya dengan baik. Sehingga kepercayaan yang terbina baik antara satu dengan yang lain menciptakan hubungan sosial yang harmonis.

\section{Menghilangkan Rasa Rendah Diri pada Anak yang Memiliki Keterbatasan}

Siapapun teman kita maka kita harus tetap menyayangi mengasihi teman kita meskipun ia memiliki keterbatasan (cacat). Guru Kobayashi juga mengajarkan bahwa seorang anak/murid tidak boleh merendahkan orang lain yang memiliki kekurangan. Hal ini membuat anak/murid di Tomoe saling mengasihi dan menyayangi satu dengan lainnya. Sehingga hubungan sosial seperti berteman akan terjalin dengan baik tanpa saling menjatuhkan dan merendahkan.

4 .Melatih Anak untuk Berani Berbicara di depan Orang banyak dan Mendengarkan dengan Baik saat Orang Lain Berbicara Dengan Kita

bahwa anak/murid harus mempunyai keberanian dan tidak boleh takut saat mengungkapkan ide/pendapat di depan orang lain. Tidak perlu risau/kwatir dulu sebelum menyampaikan, yang penting kita harus mencoba dan berusaha terlebih dahulu. Guru Kobasahi juga menyakinkan kepada anak/muridnya bahwa ketika menyampaikan ide kepada orang lain tidak harus menjadi pintar atau hebat yang penting menyampaikan gagasan terlebih dulu, apakah nanti ide diterima atau tidak, hal tersebut tidak boleh dijadikan beban, yang paling penting telah mencoba. Hubungan sosial yang baik saat kita bergantian mendengarkan apa yang kita atau orang lain sampaikan/bicarakan, sehinga sikap saling menghormati dan menghargai akan terwujud.

5. Mengajarkan Pada Anak untuk Mendapatkan sesuatu dengan Bekerja Keras / Dengan Jerih Payah Sendiri

kita harus mempunyai semangat kerja keras ketika ingin menggapai/mewujudkan sesuatu. Guru Kobayashi juga menyakinkan dengan memberi motivasi dan kepercayaan bahwa apapun kerja keras yang kita lakukan akan membuahkan hasil yang baik dan manis. Hal ini membuat anak/murid menjadi berusaha untuk melakukan hal-hal yang disukai dengan kerja keras. 


\section{DAFTAR PUSTAKA}

Alwi, Hasan,dkk. 2002. Kamus Besar Bahasa Indonesia. Jakarta:Balai Pustaka

Damono, Sapardi Djoko.2003. Sosiologi Sastra.

Kirana, Widya. 2003. Totto-Chan: Gadis Cilik di Jendela.Jakarta:Gramedia

Pustaka Utama

Kuroyanagi, Tetsuko. 1981. Madogiwa no Tottochan. Kodansha

Ratna, Nyoman Kutha.2003. Paradigma Sosiologi Sastra. Yogyakarta: Pustaka Pelajar

Sumarjo, Yacob. 1979. Masyarakat dan Sastra Indonesia. Yogyakarta: Nur Cahaya 